\title{
Baclofen Reversed Thermal Place Preference in Rats With Chronic Constriction Injury
}

\author{
K. SALTE ${ }^{1}$, G. LEA ${ }^{1}$, M. FRANEK ${ }^{1}$, S. VACULIN ${ }^{1}$ \\ ${ }^{1}$ Department of Normal, Pathological and Clinical Physiology, Third Faculty of Medicine, Charles \\ University in Prague, Prague, Czech Republic
}

Received February 4, 2015

Accepted June 26, 2015

On-line October 8, 2015

\begin{abstract}
Summary
Chronic constriction injury to the sciatic nerve was used as an animal model of neuropathic pain. Instead of frequently used reflex-based tests we used an operant thermal place preference test to evaluate signs of neuropathic pain and the effect of baclofen administration in rats with neuropathy. Chronic constriction injury was induced by four loose ligations of the sciatic nerve. Thermal place preference $\left(45^{\circ} \mathrm{C}\right.$ vs. $22^{\circ} \mathrm{C}$ and $45^{\circ} \mathrm{C}$ vs. $11^{\circ} \mathrm{C}$ ) was measured after the ligation and after the administration of baclofen in sham and experimental rats. Rats with the chronic constriction injury spent significantly less time on the colder plate compared to sham operated animals at the combination $45^{\circ} \mathrm{C}$ vs. $11^{\circ} \mathrm{C}$. After administration of baclofen $(10 \mathrm{mg} / \mathrm{kg} \mathrm{s.c.})$, the aversion to the colder plate in rats with chronic constriction injury disappeared. At the combination $45^{\circ} \mathrm{C}$ vs. $22{ }^{\circ} \mathrm{C}$, no difference in time spent on colder and/or warmer plate was found between sham and experimental animals. These findings show the importance of cold allodynia evaluation in rats with chronic constriction injury and the effectiveness of baclofen in this neuropathic pain model.
\end{abstract}

\section{Key words}

Neuropathic pain • Thermal place preference • Baclofen • Cold allodynia

\section{Corresponding author}

S. Vaculin, Department of Normal, Pathological and Clinical Physiology, Third Faculty of Medicine, Charles University in Prague, Ke Karlovu 4, 12000 Prague 2, Czech Republic.

E-mail: svaculin@lf3.cuni.cz

\section{Introduction}

Chronic constriction injury $(\mathrm{CCI})$ to the sciatic nerve of rats is a frequently used model for neuropathic pain. After the surgery, mechanical and thermal allodynia and hyperalgesia develop and last for several weeks. Both allodynia and hyperalgesia are usually measured in terms of decreased withdrawal latency either to non-nociceptive mechanical stimulation or noxious radiant heat. A crucial weak point of these procedures is that both tests are based on segmental spinal responses without cerebral processing. It has been a matter of debate for a long time whether reflex based responses are suitable for measuring neuropathic pain or not (Chapman et al. 1985, Baliki et al. 2005). The withdrawal reaction, although supraspinally modulated under normal conditions, can be seen even in spinalized animals (Kauppila et al. 1998). That means that changes in the withdrawal reactions observed after peripheral neuropathy might rather reflect changes in the spinal reflex arch than changes in the cerebral processing of pain. Pain is a subjective feeling arising at the cortical level, therefore methods requiring cerebral processing of nociceptive input and operant motor response after selection of a behavioral strategy have been introduced (Vierck et al. 2004, King et al. 2009, Marcinkiewcz et al. 2009). Operant responses in animals allow us to demonstrate the affective-motivational aspects of pain, which corresponds much better to findings in patients since the affective-motivational aspects of pain are a crucial component in patients suffering from neuropathic pain (Melczak and Casey 1968, Baliki et al. 2005). In the present study we used thermal preference test to reveal signs of neuropathic pain in $\mathrm{CCI}$ rats. 
Methods requiring cerebral processing of nociceptive input and operant motor response in rats further revealed the usefulness of cold testing in CCI rats (Vierck et al. 2005, Datta et al. 2010). Cold allodynia lasted long after recovery of enhanced mechanical sensitivity, meaning that cold allodynia is a major sign of neuropathic pain following CCI (Datta et al. 2010). Indeed, cold allodynia is one of the main symptoms of neuropathic pain in patients too (Gierthmühlen et al. 2012). Aversion to cold after CCI in rats was also presented by Sato et al. (2000), they reported that exposure to low ambient temperature aggravated painrelated behaviors in CCI male rats. Therefore, we decided to involve method requiring cerebral processing to evaluate cold allodynia in CCI rats.

Baclofen, a specific GABA-B agonist, is an effective therapeutic agent to reduce rigidity and spasms of skeletal muscles (Davidoff 1985). Besides, baclofen is used off-label for the treatment of neuropathic pain (Lynch and Watson 2006). However, it does not correspond to the findings from animal studies. Although baclofen exerted some antinociceptive effect in animal models (Hwang and Yaksh 1997, Patel et al. 2001, Franek and Vaculin 2009), the effect was attenuated under neuropathic conditions (Franek et al. 2004). Again, spinal reflex responses were used in these studies to test nociception, and thus might contribute to the discrepancy between the clinical and the experimental observations. Therefore, we used thermal place preference for evaluation of effect of baclofen in CCI rats.

The aim of the present study was, first, to determine if the thermal place preference a measurement requiring cerebral processing - would change after unilateral CCI in Wistar male rats, and second, to reveal if the change would be influenced by the administration of baclofen.

\section{Methods}

\section{Animals}

Fourteen adult male Wistar rats (Velaz, Prague, Czech Republic) weighing 250-300 g were housed with free access to food and water, and maintained under a regime with $12 \mathrm{~h}$ of light and $12 \mathrm{~h}$ of darkness per day. The mean temperature was $22 \pm 2{ }^{\circ} \mathrm{C}$, and the relative humidity equaled $55 \pm 10 \%$. The acclimation period was 5 days long. The experiment was approved by the Committee for Animal Care and Use of the Third Faculty of Medicine, Charles University, Prague, and conducted according to the guidelines of the Ethics Committee of the International Association for the Study of Pain (Zimmermann 1983). At the end of the experiments, the rats were overdosed with inhaled anesthesia.

\section{Experimental protocol}

The rats were divided into two groups - CCI and sham operated. Ten days after the surgery the nociceptive thresholds of both hind limbs were measured in both groups. Only rats exerting difference in the nociceptive thresholds were included in the CCI group. Thermal place preference was measured in both groups at the same day $-\mathrm{D} 10\left(45^{\circ} \mathrm{C}\right.$ vs. $\left.22^{\circ} \mathrm{C}\right)$ and one day after - D11 $\left(45^{\circ} \mathrm{C}\right.$ vs. $\left.11^{\circ} \mathrm{C}\right)$. The same measurements were repeated on two subsequent days (D12 for the combination of $45^{\circ} \mathrm{C}$ vs. $22{ }^{\circ} \mathrm{C}$, D13 for the combination of $45^{\circ} \mathrm{C}$ vs. $11^{\circ} \mathrm{C}$ ). For baclofen administration, the plates at thermal place preference were set at $45^{\circ} \mathrm{C}$ vs. $11^{\circ} \mathrm{C}$. Baclofen (10 mg/kg s.c., Sigma-Aldrich, dissolved in saline) was administered $50 \mathrm{~min}$ before the thermal place preference test at D14 and D15. The dose was chosen according to our previous results (Franek et al. 2004). There were six rats in each group.

\section{Surgery}

Neuropathic pain was induced by creating a chronic constriction injury according to the model of Bennett and Xie (1988). Briefly, under ketamine and xylazin anesthesia $(100 \mathrm{mg} / \mathrm{kg}$ and $16 \mathrm{mg} / \mathrm{kg}$ i.p., respectively), the left sciatic nerve was exposed and slightly ligated with four ligatures of chromic catgut (4-0). The sham group underwent the same procedure, except for the nerve ligation.

\section{Thermal place preference}

Thermal Place Preference Apparatus (Bioseb, France) was used. The rats were placed in the middle between two plates at the beginning of each test, the duration spent on each plate and number of transitions between the plates were automatically recorded during $10 \mathrm{~min}$. Time spent in between the plates was excluded. Thermal place preference (TPP) for each combination of temperatures was measured two times with a 48-h break. Percentage of time spent on the colder plate was calculated and the mean value from two measurements of TPP was recorded for analysis.

The following combinations of temperatures were used: $45^{\circ} \mathrm{C}$ vs. $22^{\circ} \mathrm{C}$ and $45^{\circ} \mathrm{C}$ vs. $11^{\circ} \mathrm{C}$. In the combination of $45^{\circ} \mathrm{C}$ vs. $11^{\circ} \mathrm{C}$, equal time spent on both 
plates was found in sham rats, and was therefore used to reveal cold aversion after CCI. The combination of $45^{\circ} \mathrm{C}$ vs. $22^{\circ} \mathrm{C}$ was used to exclude warm attraction after $\mathrm{CCI}$ and so to confirm cold aversion. Relative time spent on the colder plates was measured and compared within the groups (thermal preference) and between the groups (effect of chronic constriction injury).

In order to evaluate the effect of treatment, thermal place preference was measured on two subsequent days $50 \mathrm{~min}$ after the administration of baclofen in the same rats. According to the results of the previous experiment, only the temperature combination $45^{\circ} \mathrm{C}$ vs. $11^{\circ} \mathrm{C}$ was used. Again, thermal preference was evaluated within the group and time spent on warmer and colder was compared to the results from the previous experiment to evaluate the effect of treatment.

\section{Statistics}

Wilcoxon test was used to evaluate thermal preference within the group, t-test was employed to compare two groups (sham vs. CCI to reveal effect of chronic constriction or effect of baclofen, and values before and after administration of baclofen to reveal effect of baclofen). Statistical difference was considered significant when $\mathrm{p}<0.05$.

\section{Results}

Effect of neuropathic pain (Fig. 1)

Within the sham group, there was no thermal preference at the combination $45^{\circ} \mathrm{C}$ vs. $11^{\circ} \mathrm{C}$. The sham rats spent $41.4 \%$ on the warmer plate and $58.6 \%$ on the colder one $(\mathrm{p}=0.46)$. Within the CCI group, significant aversion to the cold plate was found $(p=0.04)$. The CCI rats spent $72.3 \%$ on the $45^{\circ} \mathrm{C}$ plate and $27.7 \%$ on the $11{ }^{\circ} \mathrm{C}$ one.

The aversion to cold in CCI group is further verified by the finding, that the CCI rats spent significantly less time on the colder plate when compared to the sham group $(27.8 \%$ and $58.6 \%$, respectively, $\mathrm{p}=0.03)$.

When comparing TPP at the combination $45^{\circ} \mathrm{C}$ vs. $22{ }^{\circ} \mathrm{C}$, neither thermal preference within any of the groups, nor difference between the sham and the CCI group was found. The sham and the CCI rats spent $42.7 \%$ and $47.7 \%$ of time on the colder plate, respectively. When comparing the $\mathrm{CCI}$ group at the combination of $45^{\circ} \mathrm{C}$ vs. $11^{\circ} \mathrm{C}$ and $45^{\circ} \mathrm{C}$ vs. $22^{\circ} \mathrm{C}$, a significant decrease of the time spent on the colder plate was found $(\mathrm{p}<0.01)$.

Regarding the number of transitions at the combination $45^{\circ} \mathrm{C}$ vs. $11^{\circ} \mathrm{C}$ between the sham and the CCI group ( $30.75 \pm 5.41$ and $11.08 \pm 1.72$, respectively), a significantly lower number was found in the CCI group $(p=0.02)$. However, when the number of transitions at combination $45^{\circ} \mathrm{C}$ vs. $22{ }^{\circ} \mathrm{C}$ was compared, no difference was found between the CCI and the sham group (33.00 \pm 7.98 and $32.44 \pm 5.36$, respectively, $\mathrm{p}=0.95$ ).

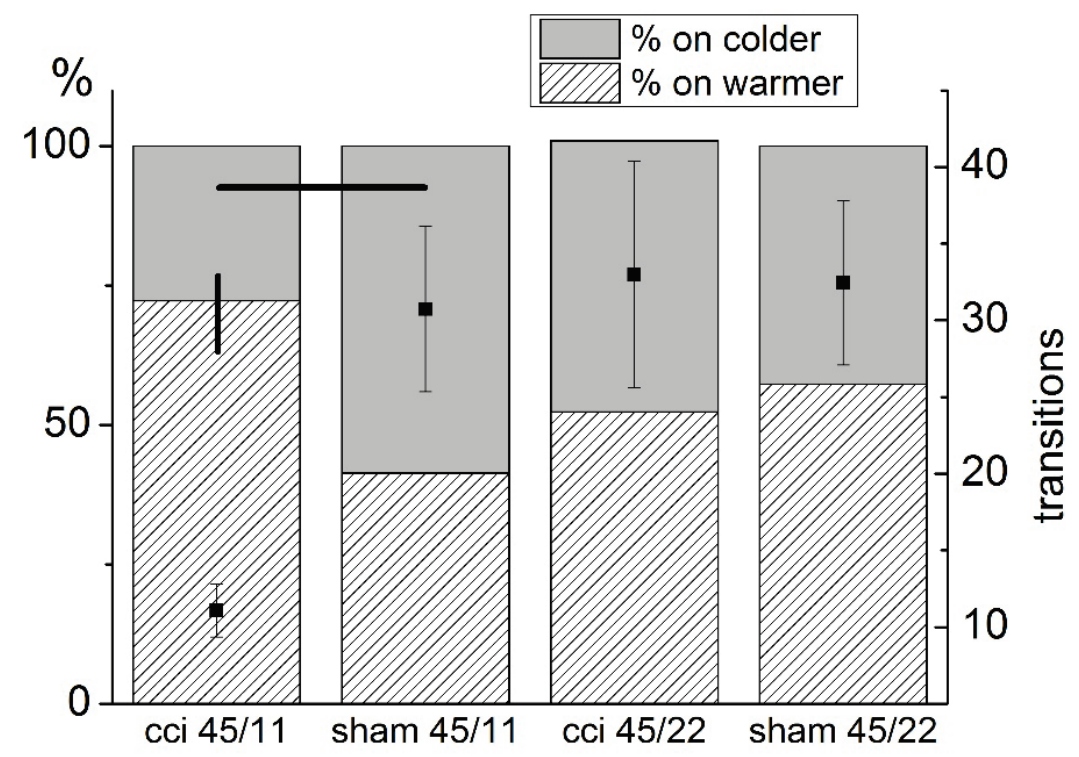

Fig. 1. Comparison of thermal place preference and number of transitions in CCI and sham rats. At the combination $45^{\circ} \mathrm{C}$ vs. $11^{\circ} \mathrm{C}$, CCI rats spent significantly less time on the colder plate compared to sham rats. CCI rats also spent significantly less time on the colder plate compared to time on the warmer plate. At the combination $45^{\circ} \mathrm{C}$ vs. $22^{\circ} \mathrm{C}$ no difference was found within the groups or between the groups. Significance $(p<0.05)$ of the time spent on plates, either within the group or between the groups, is indicated by bars. Number of transitions (right axis and black squares) was significantly lower in CCI rats only at the combination $45^{\circ} \mathrm{C}$ vs. $11^{\circ} \mathrm{C}$ but not at the combination $45^{\circ} \mathrm{C}$ vs. $22^{\circ} \mathrm{C}$. Data are expressed as mean $\pm \mathrm{SEM}$. 


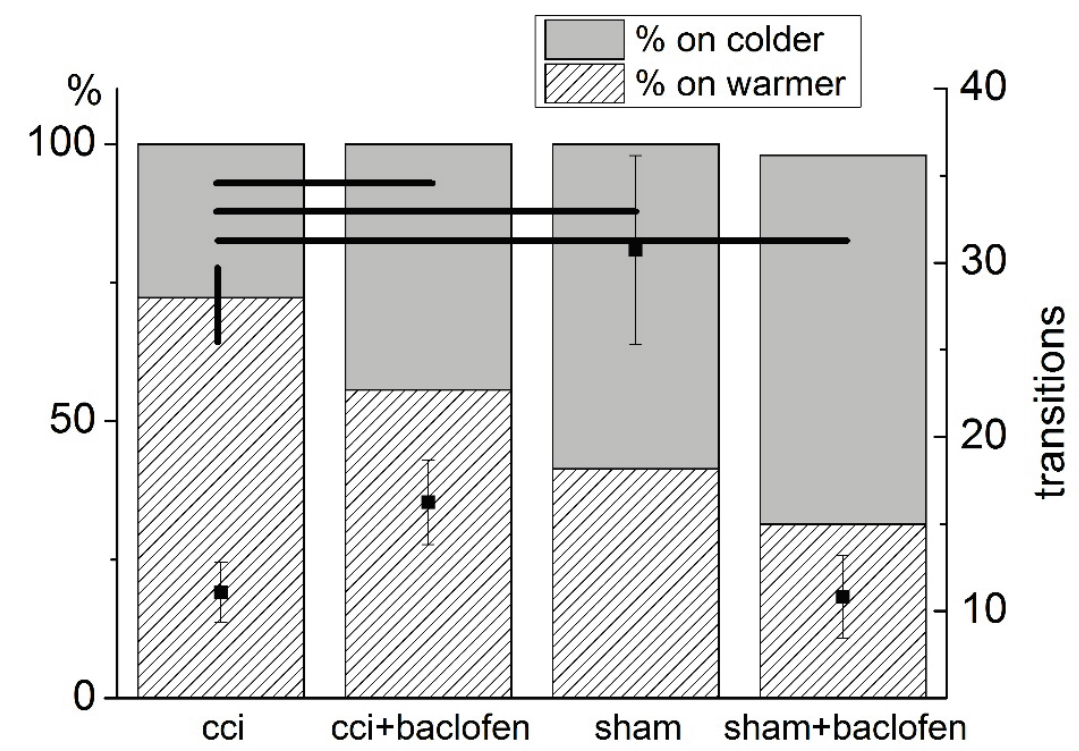

Fig. 2. Comparison of thermal place preference and number of transitions in CCI and sham rats before and after baclofen administration at the combination $45^{\circ} \mathrm{C}$ vs. $11^{\circ} \mathrm{C}$. After baclofen, CCI rats spent significantly more time on the colder plate than before the administration, and their thermal place preference did not differ from those of either sham rats or sham rats after baclofen administration. Significance $(p<0.05)$ of the time spent on plates, either within the group or between the groups, is indicated by bars. Number of transitions (right axis and black squares) significantly decreased after baclofen in sham group only, however, number of transitions after baclofen was same when compared sham and CCI group. Data are expressed as mean \pm SEM.

\section{Effect of baclofen (Fig. 2)}

Within the sham group, thermal preference was not found after the baclofen administration (the rats spent $35.3 \%$ on the warmer and $64.7 \%$ on the colder plate, $\mathrm{p}=0.12$ ). Also, when comparing time spent on the colder plate before and after the administration of baclofen in the sham group, no difference was found (before $58.8 \%$, after $64.7 \%, \mathrm{p}=0.48)$. Within the CCI group, cold aversion disappeared after the administration of baclofen (rats spent $55.8 \%$ and $44.2 \%$ on the warm and cold plates, respectively, $\mathrm{p}=0.24)$. Baclofen also significantly increased the time spent on the colder plate in the CCI group compared to the pre-treatment values $(27.7 \%$ before and $44.2 \%$ after baclofen, $\mathrm{p}=0.03$ ). Further, when comparing time spent on the colder plate in the CCI group after baclofen administration either to the sham group $(p=0.25)$ or the sham group after baclofen $(p=0.07)$, no significant difference was found.

Baclofen decreased the number of transitions in the sham group (before $30.75 \pm 5.41$, after $10.83 \pm 2.39$, $\mathrm{p}=0.02$ ), while the number of transitions in the CCI group remained unchanged (before $11.08 \pm 1.72$, after 16.25 \pm 2.44 , $\mathrm{p}=0.14)$.

\section{Discussion}

In our study we used a thermal place preference test to evaluate the effect of unilateral CCI in Wistar male rats. We found that rats after CCI preferred the warmer plate, suggesting cold allodynia. The warmer plate preference disappeared after baclofen administration, suggesting effectiveness of baclofen in animals on cold allodynia, and therefore the thermal preference test corresponded better to findings in neuropathic pain patients.

\section{Effect of CCI on thermal place preference}

Cold allodynia has not been frequently measured in rats after $\mathrm{CCI}$ and has not been considered as one of the major findings in this animal model (Baliki et al. 2005) although it is commonly found in patients suffering from neuropathic pain (Gierthmühlen et al. 2012). The presence of cold allodynia after CCI has been suggested in animal studies before due to increased duration of paw withdrawal in the acetone drop test (Choi et al. 1994). Vierck et al. (2005) used operant escape responses and thermal preference test and found that bilateral CCI in female Long-Evans rats resulted in long lasting increases in nocifensive responses to cold with no change in responses to heat. Their results were confirmed and elaborated by Datta et al. (2010).

In our study we demonstrated that cold aversion was observed also in male Wistar rats with unilateral CCI. At the combination of temperatures $45^{\circ} \mathrm{C}$ vs. $11^{\circ} \mathrm{C}$ rats after $\mathrm{CCI}$ preferred the warmer plate compared to sham operated animals, and spent more time there than on the colder plate. That is in good agreement with previous findings (Vierck et al. 2005, Datta et al. 2010).

However, such results could be attributed to either cold allodynia, or heat preference, e.g. for heat induced alleviation of pain. Since no preference for the warmer plate was found at the combination of $45^{\circ} \mathrm{C}$ vs. $22{ }^{\circ} \mathrm{C}$ in the $\mathrm{CCI}$ group, heat preference could be ruled out. Because $11^{\circ} \mathrm{C}$ is a sub-noxious cold stimulation, the 
aversion to the $11^{\circ} \mathrm{C}$ plate could be interpreted as cold allodynia.

An alternative explanation of the warmer place preference observed after CCI, could be a generalized decrease in motor activity after CCI manifesting as less transitions. We did not observe any difference in transitions between the sham and CCI groups at the $45^{\circ} \mathrm{C}$ vs. $22{ }^{\circ} \mathrm{C}$ temperature combinations, and therefore ruled this out. Thus, the decreased numbers of transitions are most likely attributable to cold allodynia and subsequently avoiding transitions to the colder plate.

When comparing to a previous comparable study (Vierck et al. 2005, Datta et al. 2010), we used unilateral $\mathrm{CCI}$, and different sex and strain of the rats. Concerning unilateral versus bilateral CCI, since the affectivemotivational aspect of pain is evaluated and not a reflex based withdrawal response, unilateral CCI likely produces the same response to cold as a bilateral one. Indeed, Walczak and Beaulieu (2006) showed in male mice that unilateral CCI induced cold allodynia observed using a thermal preference test. A drawback to using female rats is that the pain sensitivity is dependent on the estral cycle, thus either the results have to be correlated to the phase, or measurements have to be repeated through the whole cycle. Furthermore, in our previous study we demonstrated that intact Wistar female rats, regardless of the phase of cycle, were more aversive to cold stimulation than male rats (Franek et al. unpublished). Here we found, that scrotal sensitivity of males to heat delivered via the floor of the testing chamber (Vierck et al. 2005) might not be problematic for behavioral testing. Neuropathic pain models show considerable variability across rat strains. Originally, Vierck et al. (2005) showed that cold allodynia following bilateral CCI measured by thermal place preference developed in Long Evans strain rats, then it was approved also in Sprague Dawley strain rats (Datta et al. 2010), and here we demonstrated the same in Wistar rats. These results mean that cold allodynia was not unique to one strain of rats (Datta et al. 2010) and could be generally accepted as a major sign of neuropathic pain in rats following CCI.

\section{Effect of baclofen}

The cold plate aversion observed in the CCI group disappeared after the administration of baclofen, suggesting effectiveness of baclofen in the animal model. However, when studying baclofen by means of motor and thermal tests, two problems emerge. First, baclofen is known to induce myorelaxation (Davidoff 1985), thus, a general reduction in movements expressed as a decreased number of transitions after baclofen could result in increased occupancy of the colder plate. On the other hand, a) motor activity decreases in rats after baclofen at the dose of $20 \mathrm{mg} / \mathrm{kg}$ (Franek et al. 2004), i.e. two times higher than those used in the present study, b) decreased number of transitions and eventual decrease in motor activity had no effect on place preference in sham rats, (decreased number of transitions in sham rats could be attributed to lower motivation to change one plate for the other due to antinociceptive effect of baclofen, i.e. it might take longer time to decide to change the plate), and c) although decreased, the average number of transitions in the rats was high enough to allow for the operant response. This allowed the observed effects of baclofen not to be attributed to the decreased motor activity. Second, it has been demonstrated that baclofen decreases body temperature in rats (Zarrindast and Oveissi 1988), and that the withdrawal response to thermal stimulation significantly depends on skin temperatures (Vítková et al. 2014). Therefore, the effects of baclofen in thermal tests could be attributed to changes in skin and body temperatures, rather than to analgesia. However, a) Zarrindast and Oveissi (1988) showed that baclofen at the dose $10 \mathrm{mg} / \mathrm{kg}$ had no effect on body temperature one hour after administration; b) we showed that occupancy of the colder plate increased after baclofen administration in the CCI group, which is not consistent with the idea that decreased body temperature would result in decreased duration spent on the colder plate, and c) no effect of baclofen on the thermal preference was found in sham operated rats. This strengthened our conviction that the observed effects of baclofen could be attributable to its analgetic properties.

The antinociceptive effect of baclofen has been described in animal studies when using a spinal-reflex based test (Hwang and Yaksh 1997, Patel et al. 2001). Regarding the mechanism of action, the presynaptic inhibition of calcium channels resulting in decrease in the number of action potentials has been suggested as a probable explanation (Fukuhara et al. 2013). In our previous study, we showed that the antinociceptive effect (i.e. result of reflex-based test) of baclofen was attenuated in rats with chronic constriction injury (Franek et al. 2004). Our previous results corresponded to the findings of Castro-Lopes et al. (1995), who described the decrease in the number of GABA-B binding sites in lamina II of the spinal cord after the sciatic nerve injury. All these findings suggest the dorsal horn of the spinal cord as 
a site of baclofen action.

In this study we demonstrated that using the thermal place preference test requiring cerebral processing, baclofen exerted an analgesic effect in the same animal model, contradicting findings from the spinal cord reflex-based study. Therefore, site of baclofen action in rats with neuropathic pain might be rather located at the supraspinal level. This suggestion supports the notion, that the supraspinal site is the most sensitive to the action of baclofen (Proudfit and Levy 1978).

Further, since baclofen has been shown to be effective in the treatment of neuropathic pain in humans (Taira et al. 1995, Middleton et al. 1996, Harmer and Larson 2002, Kumru et al. 2013), our present results comply better with the findings from clinical practice. The conclusion to use operant behavior-based tests in evaluation of signs of neuropathic pain in animal models (Vierck and Yezierski 2015) is strongly encouraged by our results.

\section{Conclusions}

Our results support the use of the thermal place preference test for thermal sensitivity evaluation in rats, and especially of cold stimulation for the assessment of neuropathic pain. Thermal place preference is a simple method to use and provides better insight into behavioral changes after induction of peripheral neuropathy than the withdrawal response. In our study we showed that unilateral CCI induced cold allodynia, which was reversed by baclofen administration, which is in good agreement with findings in patients.

\section{Conflict of Interest}

There is no conflict of interest.

\section{Acknowledgements}

Research supported by IGA NT/14484 and by the Charles University research programme PRVOUK P33.

\section{References}

BALIKI M, CALVO O, CHIALVO DR, APKARIAN AV: Spared nerve injury rats exhibit thermal hyperalgesia on an automated operant dynamic thermal escape task. Mol Pain 1: 18, 2005.

BENNETT GJ, XIE YK: A peripheral mononeuropathy in rat that produces disorders of pain sensation like those seen in man. Pain 33: 87-107, 1988.

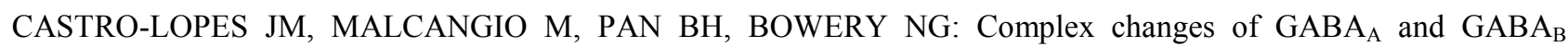
receptor binding in the spinal cord dorsal horn following peripheral inflammation or neurectomy. Brain Res 679: 289-297, 1995.

CHAPMAN CR, CASEY KL, DUBNER R, FOLEY KM, GRACELY RH, READING AE: Pain measurement: an overview. Pain 22: 1-31, 1985.

CHOI Y, YOON YW, NA HS, KIM SH, CHUNG JM: Behavioral signs of ongoing pain and cold allodynia in a rat model of neuropathic pain. Pain 59: 369-376, 1994.

DATTA S, CHATTERJEE K, KLINE RH, WILEY RG: Behavioral and anatomical characterization of the bilateral sciatic nerve chronic constriction (bCCI) injury: correlation of anatomic changes and responses to cold stimuli. Mol Pain 6: 7, 2010.

DAVIDOFF RA: Antispasticity drugs: mechanisms of action. Ann Neurol 17: 107-116, 1985.

FRANEK M, VACULÍN S, ROKYTA R: GABA(B) receptor agonist baclofen has non-specific antinociceptive effect in the model of peripheral neuropathy in the rat. Physiol Res 53: 351-355, 2004.

FRANEK M, VACULIN S: Role of GABA(B) receptor agonist baclofen in acute pain modulation during the early postnatal period. Pharmacology 84: 104-110, 2009.

FUKUHARA K, KATAFUCHI T, YOSHIMURA M: Effects of baclofen on mechanical noxious and innocuous transmission in the spinal dorsal horn of the adult rat: in vivo patch-clamp analysis. Eur J Neurosci 38: 33983407, 2013.

GIERTHMÜHLEN J, MAIER C, BARON R, TÖLLE T, TREEDE RD, BIRBAUMER N, HUGE V, KOROSCHETZ J, KRUMOVA EK, LAUCHART M, MAIHÖFNER C, RICHTER H, WESTERMANN A: Sensory signs in complex regional pain syndrome and peripheral nerve injury. Pain 153: 765-774, 2012. 
HARMER JP, LARSON BS: Pain relief from baclofen analgesia in a neuropathic pain patient who failed opioid and pharmacotherapy: case report. J Pain Palliat Care Pharmacother 16: 61-64, 2002.

HWANG JH, YAKSH TL: The effect of spinal GABA receptor agonists on tactile allodynia in a surgically-induced neuropathic pain model in the rat. Pain 70: 15-22, 1997.

KAUPPILA T, KONTINEN VK, PERTOVAARA A: Influence of spinalization on spinal withdrawal reflex responses varies depending on the submodality of the test stimulus and the experimental pathophysiological condition in the rat. Brain Res 797: 234-242, 1998.

KING T, VERA-PORTOCARRERO L, GUTIERREZ T, VANDERAH TW, DUSSOR G, LAI J, FIELDS HL, PORRECA F: Unmasking the tonic-aversive state in neuropathic pain. Nat Neurosci 12: 1364-1366, 2009.

KUMRU H, KOFLER M, FLORES MC, PORTELL E, ROBLES V, LEON N, VIDAL J: Effect of intrathecal baclofen on evoked pain perception: an evoked potentials and quantitative thermal testing study. Eur J Pain 17: 10391047, 2013.

LYNCH ME, WATSON CP: The pharmacotherapy of chronic pain: a review. Pain Res Manag 11: 11-38, 2006.

MARCINKIEWCZ CA, GREEN MK, DEVINE DP, DUARTE P, VIERCK CJ, YEZIERSKI RP: Social defeat stress potentiates thermal sensitivity in operant models of pain processing. Brain Res 1251: 112-120, 2009.

MELCZAK R, CASEY KL: Sensory, motivational, and central control determinants of pain. A new conceptual model. In: The Skin Senses. DR KENSHALO (ed), Charles C. Thomas, Springfield, 1968, pp 423-443.

MIDDLETON JW, SIDDALL PJ, WALKER S, MOLLOY AR, RUTKOWSKI SB: Intrathecal clonidine and baclofen in the management of spasticity and neuropathic pain following spinal cord injury: a case study. Arch Phys Med Rehabil 77: 824-826, 1996.

PATEL S, NAEEM S, KESINGLAND A, FROESTL W, CAPOGNA M, URBAN, L, FOX A: The effects of GABA(B) agonists and gabapentin on mechanical hyperalgesia in models of neuropathic and inflammatory pain in the rat. Pain 90: 217-226, 2001.

PROUDFIT HK, LEVY RA: Delimitation of neuronal substrates necessary for the analgesic action of baclofen and morphine. Eur J Pharmacol 47: 159-166, 1978.

SATO J, MORIMAE H, TAKANARI K, SEINO Y, OKADA T, SUZUKI M, MIZUMURA K: Effects of lowering ambient temperature on pain-related behaviors in a rat model of neuropathic pain. Exp Brain Res 133: 442-449, 2000.

TAIRA T, KAWAMURA H, TANIKAWA T, KAWABATAKE H, ISEKI H, UEDA A, TAKAKURA K: A new approach to the control of central deafferentation pain - spinal intrathecal baclofen. Acta Neurochir Suppl 64: 136-138, 1995.

VIERCK CJ, YEZIERSKI RP: Comparison of operant escape and reflex tests of nociceptive sensitivity. Neurosci Biobehav Rev 51: 223-242, 2015.

VIERCK CJ, KLINE R, WILEY RG: Comparison of operant escape and innate reflex responses to nociceptive skin temperatures produced by heat and cold stimulation of rats. Behav Neurosci 118: 627-635, 2004.

VIERCK CJ, ACOSTA-RUA AJ, JOHNSON RD: Bilateral chronic constriction of the sciatic nerve: a model of longterm cold hyperalgesia. J Pain 6: 507-517, 2005.

VÍTKOVÁ J, LOUČKA M, BOČEK J, VACULÍN Š: The effect of acclimatization and ambient temperature on heat withdrawal threshold in rats. Eur J Pain 19: 21-27, 2015.

WALCZAK JS, BEAULIEU P: Comparison of three models of neuropathic pain in mice using a new method to assess cold allodynia: the double plate technique. Neurosci Lett 399: 240-244, 2006.

ZARRINDAST MR, OVEISSI Y: GABAA and GABAB receptor sites involvement in rat thermoregulation. Gen Pharmacol 19: 223-226, 1988.

ZIMMERMANN M: Ethical guidelines for investigations of experimental pain in conscious animals. Pain 16: 109-110, 1983. 